\title{
Radiation Potential of Extremely Low Frequency (ELF) Magnetic Field to Increase Tobacco Production
}

\author{
Sudarti ${ }^{1}$, Singgih Bektiarso ${ }^{2}$, Sri Handono Budi Prastowo ${ }^{3}$, \\ Fatholla Fuad $^{4}$, Ita Jeny Trisnawati ${ }^{5}$ \\ 1,2,3,4,5,6 Physics Education Study Program, University of Jember, Indonesia \\ ${ }^{1}$ sudarti.fkip@unej.ac.id \\ 2 singgih.fkip@unej.ac.id \\ ${ }^{3}$ srihandono.fkip@unej.ac.id \\ 4akhiifuad@gmail.com \\ 5150210102053@students.unej.ac.id
}

\begin{abstract}
ELF magnetic field has many advantages, in addition to being a non-ionizing radiation, it is also able to penetrate almost any material. Several research results prove that exposure to ELF magnetic field can trigger the growth of tomato plants Ranti (Sari et al, 2015) and large chili plants (Handoko et al, 2017). The underlying mechanism for this is that exposure to ELF magnets can increase intracellular calcium, which can lead to increased cell proliferation. Excess magnetic field ELF is expected to be an alternative solution to the problems faced by tobacco farmers, which is the decline of the production of tobacco. Simple and inexpensive solutions need to be sought. Therefore, this study proves the effect of ELF magnetic field on increasing the leaf mass of tobacco. The sample of this research is tobacco seed exposed to ELF magnetic field after soaked in water for 24 hours. The variations in the intensity of the ELF magnetic field used in this study were $300 \mu \mathrm{T}, 500 \mu \mathrm{T}$ and $700 \mu \mathrm{T}$ and variations of 45 minutes and 60 minutes of exposure time. The results of One Way Anova analysis of this research data proves that exposure to the ELF magnetic field significantly increases the wet mass of leaf tobacco production. The highest wet mass of tobacco leaf was obtained in the group exposed to the magnetic field ELF $500 \mu \mathrm{T}$ for 60 minutes. In conclusion, that exposure to ELF magnetic field has an effect on increasing wet mass of leaf tobacco production.
\end{abstract}

\section{Extremely Low Frequency, Leaf Mass, Length of Exposure}

\section{INTRODUCTION}

Extremely Low Frequency (ELF) magnetic field radiation is a component of the ELF electromagnetic wave spectrum at frequencies less than $300 \mathrm{~Hz}$ (Tarigan, 2013). When compared with gamma ray radiation, ELF magnetic field radiation has something in common. They both are able to penetrate almost any material. But they have a difference. The radiation of gamma rays are ionizing radiation and magnetic fields' radiation are non-ionizing radiation. This condition gives insight that ELF magnetic field radiation provides a lower risk of side effects than gamma rays but, the utilization of ELF magnetic field radiation to this day is not much compared to gamma rays.

Yalcin and Erdem (2012) report that the response of biological matter by exposure to the ELF magnetic field is through interaction with cell membranes, and has an effect on the change in cell membrane semipermeability characteristics and changes in lipid and protein configuration of the membrane, which has an impact on increase of intracellular calcium. Given the role of calcium is very important as a second massanger of the celluler process, intracelullar calcium levels are needed in various celullar processes. An increase in intracellular calcium levels affects the increase of cell proliferation, but if the increase of intracellular calcium levels are very high it will have an impact on cell death (Sudarti, 2015).

Extremely Low Frequency (ELF) $500 \mu \mathrm{T}$ magnetic field exposure for 50 minutes affects the growth and weight of oyster mushrooms (Sudarti et al, 2017). While Handoko (2016) states that exposure of Extremely Low Frequency (ELF) $300 \mu \mathrm{T}$ magnetic field for 60 and 90 minutes has a positive effect on the height of big red chili (Capsicum annum L.) and the number of leaves produced by big red chili (Capsicum annum L. ). Mardhika, 2017, proves that exposure to the $\mu$ T ELF600 magnetic field for 70 minutes can improve the growth of ear mushrooms

Based on these results, it is expected that ELF magnetic field radiation can be a useful alternative solution to the tobacco productivity declining problem. Therefore this study was conducted to prove that the radiation of the ELF magnetic field has an influence on the mass of tobacco leaf production. 


\section{RESEARCH METHOD}

This research is a laboratory experimental study with Extremely Low Frequency (ELF) magnetic field radiation treatment. The sample of this research is seeds of tobacco seeds soaked in warm water for 36 hours. After being drained, they are placed in 7 saucers, each cup filled with 50 seeds of tobacco seed. Then, they are exposed to an ELF magnetic field with variations in intensity of ELF $300 \mu \mathrm{T}, 500 \mu \mathrm{T}$, and $700 \mu \mathrm{T}$ magnetic fields and with variations of exposure time for 45 minutes and 60 minutes. Tobacco seeds not exposed to the ELF magnetic field are treated as controls. Based on the variation of exposure of ELF magnetic field and the variation of exposure time, the sample of this study consisted of 7 groups, i.e. groups exposed to $300 \mu \mathrm{T}$ magnetic field for 45 minutes (E-300,45), group exposed to $300 \mu \mathrm{T}$ magnetic field for 60 minutes (E-300,60), group exposed to $500 \mu \mathrm{T}$ magnetic field for 45 minutes (E-500,45), group exposed to $500 \mu \mathrm{T}$ magnetic field for 60 minutes (E-500,60), group exposed to magnetic field $700 \mu \mathrm{T}$ for 45 minutes $(\mathrm{E}-700,45)$, the group exposed to $700 \mu \mathrm{T}$ magnetic field for 60 minutes (E-700,60), and the control group (K).

Independent variable in this research is Extremaly Low Frequency (ELF) magnetic field. The radiation source of ELF magnetic field in this research is ELF-Sources. The ELF magnetic field exposure mechanism is performed by dropping the tobacco seed sample plate into the ELF-Sources exposure space. Furthermore, a strong current and voltage regulation is made by rotating the regulator panel, the voltage value is made as small as possible and the electric current is magnified to produce the intensity of radiation of the more dominant ELF magnetic field and the ELF field radiation is set to approximate the natural electric field of about $4 \mathrm{~V} / \mathrm{cm}$, as shown in the picture as follows.

The process of exposure of the magnetic field in the ELF-Source exposure space is as shown in the following figure.

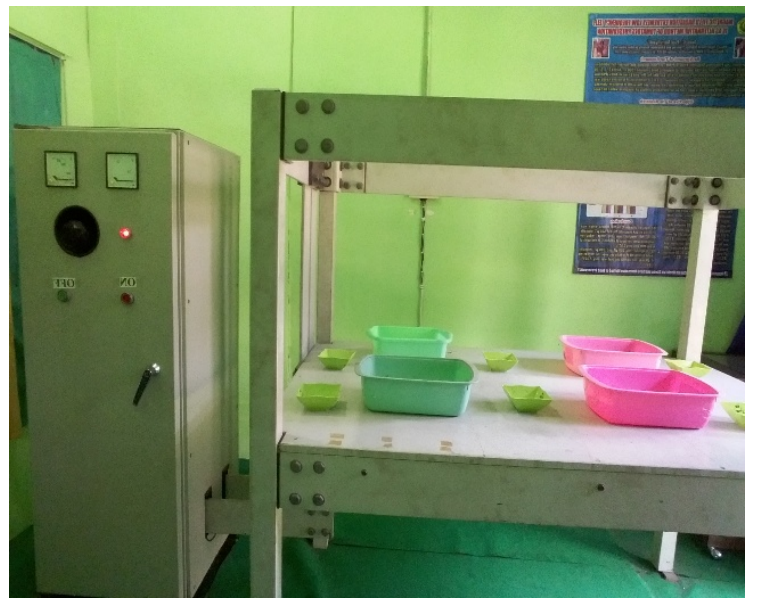

Fig 1. ELF Magnetic Field Exposure Process on Tobacco Seeds (source: author)

After all samples of tobacco seeds are exposed to ELF magnetic field, then they were sowed in the seedbed medium for 7 days ( 1 week). Then on the 8 th day, the tobacco seeds were planted in the plantback and the growth was observed. Measurement of tobacco leaf production was done by measuring wet mass and dry mass of tobacco leaf production at the end of week 7 (49th day) after sowing.

The result data of this research were then analyzed descriptively and statistically analyzed by using One Way Anova analysis to determine the intensity and the duration of ELF magnetic field exposure that gives the most influence on the increase of wet mass and dry mass of tobacco leaf production on 49th day.

\section{RESULT AND DISCUSSION}

Measurement of tobacco leaf production was done by measuring the wet mass and dry mass of tobacco leaf on tobacco plants at the 49th day after the sowing. Each group was randomly picked from 10 tobacco trees, and each plant was selected for the three widest leaves for wet mass mass and leaf dry mass using the Ohauss Balance. The average results of wet tobacco leaf mass measurements in the 7 sample groups are presented in Table 1. as follows. 
Table 1 Descriptives Mean of the Wet Mass of the Tobacco Leaf

\begin{tabular}{|c|c|c|c|}
\hline Group & $\mathbf{N}$ & Mean (gram) & Std. Deviation \\
\hline Kontrol & 10 & 1,5670 & 0,01494 \\
\hline E-300,45 & 10 & 1,7800 & 0,01491 \\
\hline E-300,60 & 10 & 1,8300 & 0,02625 \\
\hline E-500,45 & 10 & 1,8990 & 0,01370 \\
\hline E-500,60 & 10 & 2,0300 & 0,03432 \\
\hline E-700,45 & 10 & 1,8050 & 0,03028 \\
\hline E-700,60 & 10 & 1,7550 & 0,03028 \\
\hline
\end{tabular}

(source: author)

Based on Table 1, it descriptively shows the average wet mass of tobacco leaf and standard deviation in 7 groups of research samples. The average wet mass of tobacco leaf in the control group was 1.5670 grams lower than the other groups. The highest wet mass of tobacco leaf occurs in the group of plants which were exposed to the magnetic field ELF $500 \mu \mathrm{T}$, for 60 minutes i.e. 2.0300 grams,

Furthermore, to be more clear in describing the result data of wet leaf mass measurement in 7 research groups, a graph is presented as follows.

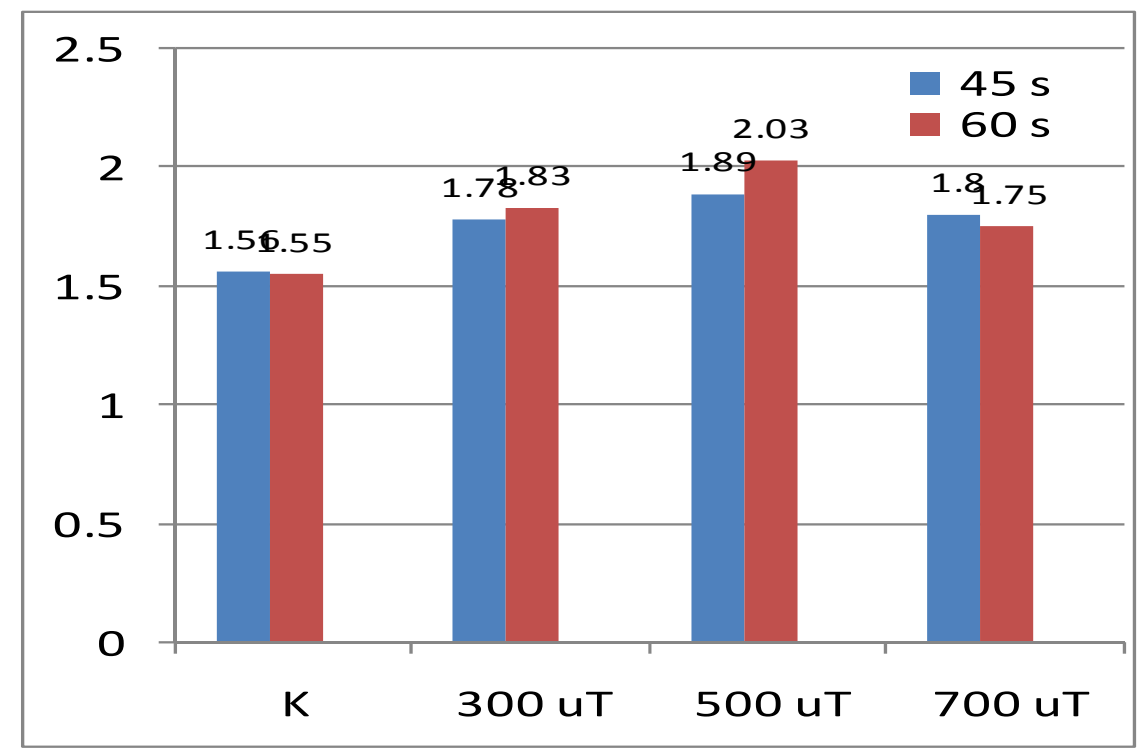

Fig 2. Everage Wet Mass (gram) of Tobacco Leaf at the age of 49 days (source: author)

The data presented in Table 1 and Graph 1 appear consistent. Wet tobacco leaf masses in the group whose seeds exposed to the ELF intensity field of $300 \mu \mathrm{T}, 500 \mu \mathrm{T}$, or $700 \mu \mathrm{T}$ were greater than the control group. The wet mass of tobacco leaves in the group exposed to the magnetic field ELFof $500 \mu \mathrm{T}$ for 45 minutes or 60 minutes is greater than in the other groups. The largest tobacco leaf mass was obtained in the group exposed to the magnetic field ELF of $500 \mu \mathrm{T}$ for 60 minutes. This suggests that descriptively there appears to be an increase in the wet mass of tobacco leaf production in the six research groups exposed to the ELF magnetic field compared to the control group.

Furthermore, to ascertain whether the increase of wet tobacco leaf mass in the group exposed to the ELF magnetic field occurred significantly, a One Way Anova statistical analysis was performed. Normal distribution test results using Kolmogorov-Smirnov Test, proved that the data of wet tobacco leaf mass measurements in 7 study groups were normally distributed with $\mathrm{p}>0.05$. Furthermore the results of One Wway Anova analysis are presented in Table. 2 as follows. 
Table 2 One Way Anova Analysis of Wet Mass of Tobacco Leaf in 7 Sample Groups

\begin{tabular}{|c|c|c|c|c|c|}
\hline & Sum of Squares & df & Mean Square & F & Sig. \\
\hline Between Groups & 1,197 & 6 & 0,200 & 322,317 & 0,000 \\
Within Groups & 0,039 & 63 & 0,001 & & \\
Total & 1,236 & 69 & & & \\
\hline
\end{tabular}

(source: author)

Table. 2 One Way Anova analysis results on the wet mass of 7 groups of research samples yield significant value $p=0,000$. This proves that the average of wet tobacco leaf mass among 7 groups of research samples is significantly different.

Furthermore, to know which groups differ significantly, the Post Hoc Tests analysis is performed, as presented in the following Table 3 .

Table 3 Post Hoc Tests Analysis Result

\begin{tabular}{|c|c|c|c|c|}
\hline (I) Group & (J) Group & Mean Difference (I-J) & Std. Error & Sig. \\
\hline \multirow{3}{*}{ Kontrol } & E-300,45 & $-0,21300^{*}$ & 0,01113 & 0,000 \\
\cline { 2 - 5 } & E-300,60 & $-0,26300^{*}$ & 0,01113 & 0,000 \\
\cline { 2 - 5 } & E-500,45 & $-0,33200^{*}$ & 0,01113 & 0,000 \\
\cline { 2 - 5 } & E-500,60 & $-0,46300^{*}$ & 0,01113 & 0,000 \\
\cline { 2 - 5 } & E-700,45 & $-0,23800^{*}$ & 0,01113 & 0,000 \\
\cline { 2 - 5 } & E-700,60 & $-0,18800^{*}$ & 0,01113 & 0,000 \\
\hline
\end{tabular}

The mean difference is significant at the 0.05 level.

(source: author)

Based on Table. 3 it is proved that the average wet mass of leaf tobacco production in 6 groups of research samples in ELF field exposure is significantly $(p<0.05)$ greater than control group. This proves that exposure to the ELF magnetic field can significantly increase the production of wet tobacco leaf mass.

The measurement result of tobacco leaf dry mass of 7 groups sample is presented in Table 4. as follows.

Table 4 Desciptives Mean of the Dry Mass Tobacco Leaf

\begin{tabular}{|c|c|c|c|}
\hline Group & $\mathrm{N}$ & Mean & Std. Deviation \\
\hline K & 10 & 0,1520 & 0,02974 \\
\hline E-300,45 & 10 & 0,1400 & 0,01826 \\
\hline E-300,60 & 10 & 0,1620 & 0,02616 \\
\hline E-500,45 & 10 & 0,1830 & 0,02908 \\
\hline E-500,60 & 10 & 0,1900 & 0,02582 \\
\hline E-700,45 & 10 & 0,2200 & 0,02582 \\
\hline E-700,60 & 10 & 0,1740 & 0,02171 \\
\hline
\end{tabular}

(source: author)

Table 4 shows descriptively the average dry mass of tobacco leaf and standard deviation in 7 groups of research samples. The average dry mass of tobacco leaves in the control group was 0.1520 gram lower than the other research groups. The highest dried tobacco leaf mass occurred in the plant group where the germination was exposed to the magnetic field ELF of $500 \mu \mathrm{T}$, for 60 minutes i.e 0.2200 gram.

Furthermore, to be more clear in describing the measurements data of leaf tobacco dry mass in 7 research groups, a graph is presented as follows. 


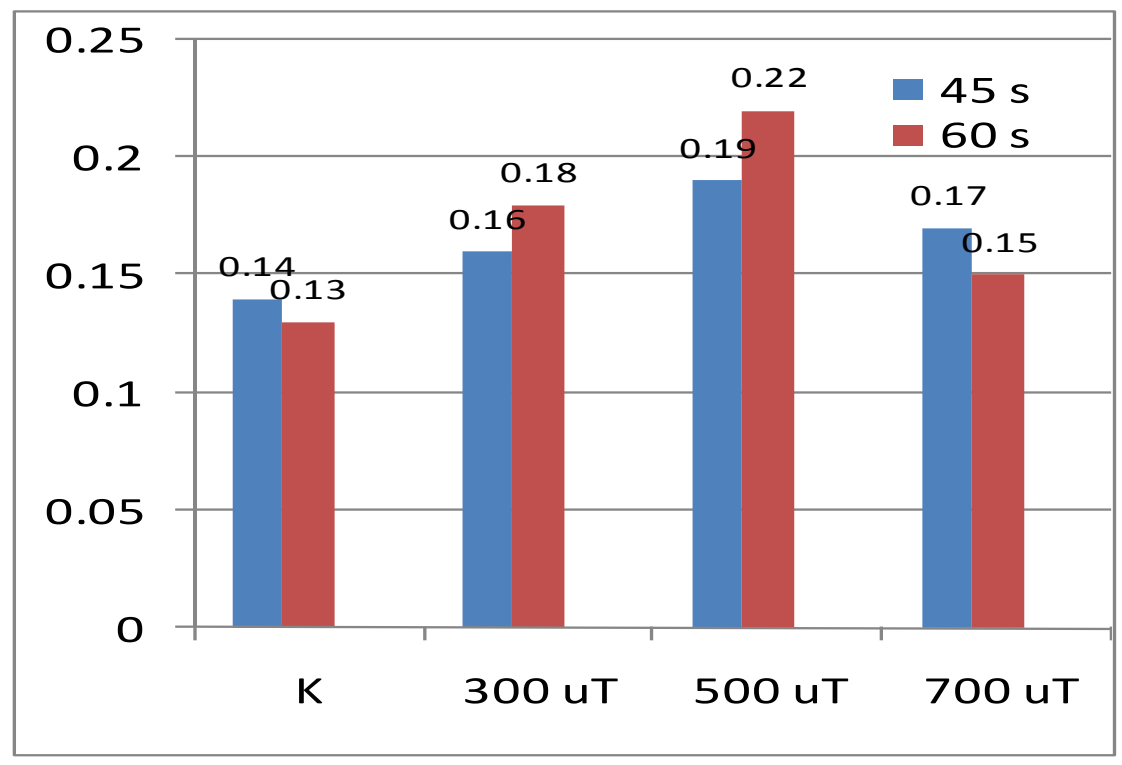

Fig. 3. Everage Dry Mass of (gram) Tobacco Leaf at the age of 49 days (source: author)

Descriptive analysis was conducted based on data from the results of the research in Table 4, and Graph 2. It appears that the dry mass of tobacco leaves in the group whose seeds were exposed to the ELF intensity field of $300 \mu \mathrm{T}, 500 \mu \mathrm{T}$, and $700 \mu \mathrm{T}$ are greater than the control group. The tobacco leaf dry mass in the group exposed to the ELF of $500 \mu \mathrm{T}$ magnetic field for 45 minutes and 60 minutes was greater than in the other groups, but the dryest mass of the largest tobacco leaf was obtained in the group exposed to an ELF $500 \mu \mathrm{T}$ magnetic field for 60 minutes.

This indicates that descriptively it appears that there is an increase of dry mass of tobacco leaf production in 6 groups of study which is exposed to ELF magnetic field compared to control group.

Furthermore, to determine whether the increase of dry mass of tobacco leaf production in groups exposed to ELF magnetic field occurs significantly, then One Way Anova statistical analysis was done. Normal distribution test results using Kolmogorov-Smirnov Test, proved that the data of dry leaf tobacco mass measurements in 7 study groups were normal with distribution $p>0,05$. Furthermore the results of One Wway Anova analysis are presented in Table.5 as follows.

\begin{tabular}{|c|c|c|c|c|c|}
\hline \multicolumn{1}{|c|}{ Table 5 One Way Anova Analysis Result on the Dry Mass of Tobacco Leaf } \\
\hline & Sum of Squares & df & Mean Square & F & Sig. \\
\hline Between Groups & 0,042 & 6 & 0,007 & 10,856 & 0,000 \\
Within Groups & 0,041 & 63 & 0,001 & & \\
Total & 0,083 & 69 & & & \\
\hline
\end{tabular}

(source: author)

Table 5 One Way Anova analysis results on the dry mass of 7 groups of research samples yielded significant value $p=0,000$. This proves that the average dry mass of tobacco leaves between 7 groups of research samples is significantly different.

Furthermore, to know which groups differ significantly, then Post Hoc Tests analysis was done as presented in the following Table 6. 


\begin{tabular}{|c|c|c|c|c|}
\hline (I) Group & (J) Group & Mean Difference (I-J) & Std. Error & Sig. \\
\hline \multirow{3}{*}{ Kontrol } & E-300,45 &,- 02200 & 0,01140 & 0,058 \\
\cline { 2 - 5 } & E-300,60 &,$- 04300^{*}$ & 0,01140 & 0,000 \\
\cline { 2 - 5 } & E-500,45 &,$- 05000^{*}$ & 0,01140 & 0,000 \\
\cline { 2 - 5 } & E-500,60 &,$- 08000^{*}$ & 0,01140 & 0,000 \\
\cline { 2 - 5 } & E-700,45 &,$- 03400^{*}$ & 0,01140 & 0,004 \\
\cline { 2 - 5 } & E-700,60 &,- 01200 & 0,01140 & 0,297 \\
\hline
\end{tabular}

The mean difference is significant at the 0.05 level. (source: author)

Based on Table 5, the results of Post Hoc Tests analysis showed that the dry leaf of tobacco leaf in the 6 groups that at the time of seeding was exposed to ELF magnetic field was significantly different $(p<0.05)$ than the control group.

If confirmed with Graph 2, it appears that the tobacco leaf in the group exposed to a $500 \mu \mathrm{T}$ intensity ELF magnetic field for 60 minutes yields the largest dry leaf mass compared to the other groups. This proves that exposure to the $500 \mu \mathrm{T}$ ELF magnetic field can increase the production of tobacco leaf.

The growth of 7 tobacco research groups on the 49th day is presented in picture 2 below.

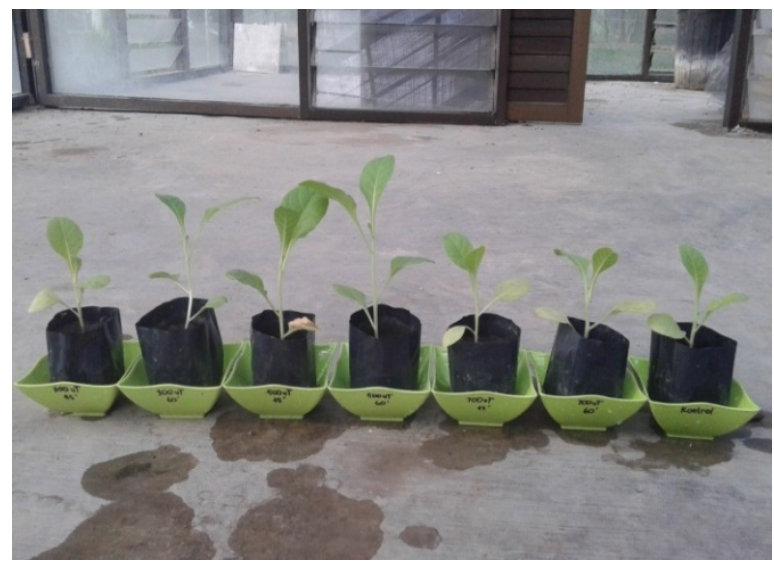

Fig 4. Growth at day 49th (source: author)

Magnetic fields and electric fields are components of electromagnetic waves that have different characteristics. The magnetic field is capable of penetrating almost any material, but the electric field is not capable of such a thing. Just as described in Picture 3 below.

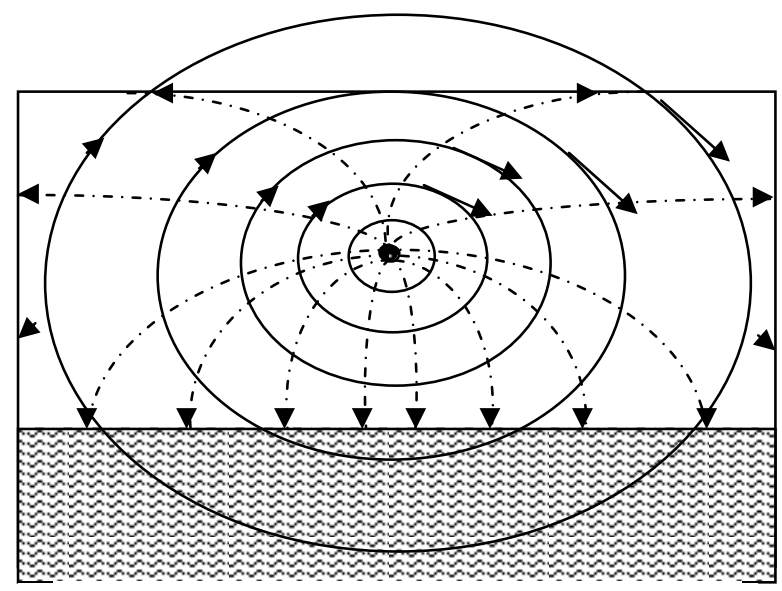

Fig 5. Electric Field and Magnetic Field Line

(Source : Darwanto, 1997)

While the ELF magnetic field is able to penetrate almost any material, the effect is not ionizing. This is the characteristic that allows the ELF magnetic field to have a very large benefit. 
The biophysics mechanisms that underlie the interaction of the ELF magnetic field with biological matter are through direct interaction with the cell membrane and will induce cell response in the form of increased intracellular calcium. Intracellullar calcium at the appropriate level plays an important role in various celullar processes, especially the proliferation cell process. Therefore, the ELF magnetic field affects cell proliferation and breeding of variety of plants including tobacco plants.

According to Faraday's law, if the human body or any other organism is exposed to a magnetic field changes over time (alternating magnetic fields) it can generate an electric field that is perpendicular to the magnetic field, causing an eddy current flow. The relation of the electric field (E) it produces and the magnetic field (B) is expressed by the formula:

$$
\mathrm{E}=\pi \mathrm{rfB}
$$

Note :

$r=$ the radius distance of material exposed to the conductor of the magnetic field exposure source $(\mathrm{m})$

$\mathrm{f}=$ frequency $(\mathrm{Hz})$

$\mathrm{B}=$ intensity of the magnetic field $(\mathrm{T}=$ tesla, $\mathrm{G}=$ gauss, $1 \mathrm{~T}=104 \mathrm{G})$

$\pi=$ constants $=3,14$

Calculation of the current density by induction of the magnetic field on the human body can use ellipsoidal model. Based on the value of the average human body conductivity of $0.2 \mathrm{~S} / \mathrm{m}$, the maximum induced current density is:

$$
\mathrm{Jm} \sim 0,25 f \mathrm{~B}
$$

Note :

$\mathrm{Jm}=$ electric current density $\left(\mathrm{A} / \mathrm{m}^{2}\right)$

$f=$ frequency of magnetic field $(\mathrm{Hz})$

$\mathrm{B}=$ intensity of magnetic field $(\mathrm{T})$

Based on the estimation using the formula above, the magnetic field at frequency $60 \mathrm{~Hz}(f)$, with intensity $500 \mu \mathrm{T}(\mathrm{B})$ can produce current density (J) of $0.03 \mathrm{~A} / \mathrm{m} 2$.

It was reported that the current density of $10-3 \mathrm{~A} / \mathrm{m} 2$ and $1 \mathrm{~A} / \mathrm{m} 2$ is a range of minimum values of current density that can stimulate the cell. In relation to the possible biological effects, the intensity of the ELF magnetic field is classified as a weak field i.e the intensity of the magnetic field at an intensity of less than 100 $\mu \mathrm{T}$ as non-thermal intensity, and the intensity of the high magnetic field is magnetic field intensity $\geq 1000 \mu \mathrm{T}$. include:

Valberg PA, 1997, reports that the mechanism of electromagnetic field interaction physics of ELF may

1. Electromagnetic field transfer of ELF energy can change the velocity of the ion or the charge of cell membrane proteins and receptor proteins, even though the energy is far below the biomolecules in the cell itself.

2. The electric field gives force to the charge and the moment of electricity, although the force is very small than the biological force itself.

3. The magnetic moment of ferromagnetic particles and free radical molecules interact with the magnetic field, but the sensors of the cell's magnets are not found in humans, and the modification of radical recombination rates by EMF in biological systems is a major problem.

4. Theoretically the interaction of electromagnetic fields of ELF is through oscillation or transfer of biomolecule ion orbits, but some experimental tests did not find a predicted effect.

Several studies have shown that exposure to the ELF magnetic field can increase cell proliferation or growth in plants. Exposure to ELF magnetic field with $50 \mu \mathrm{T}$ intensity for 50 minutes in oyster mushroom seeds can increase the production of oyster mushroom wet mass, but seeds exposed for 70 minutes resulted in the decrease of the wet mass of the production of oyster mushrooms (Sudarti, 2017).

In accordance with the concept of biophysics and the results of previous studies, this study provides a new scientific discourse, that the relatively cheap, easy to get, and safe $500 \mu \mathrm{T}$ ELF magnetic field radiation is proven to be very useful to trigger the growth of tobacco plants safely.

\section{CONSCLUSION AND SUGGESTION}


Based on the results of statistical analysis and discussions that have been described, it can be concluded that magnetic field radiation Extremely Low Frequency (ELF) can increase the production of tobacco leaves, both wet and dry mass. The results of this research found that an effective dose of ELF magnetic field to increase the productivity of tobacco leaves is magnetic field radiation with intensity of $500 \mu \mathrm{T}$ for 60 minutes.

Important thing that needs to be understood based on the result of this research is that radiation of magnetic field is a safe, cheap, and easy to get.

Based on the results and discussion then suggestions that can be given are as follows; 1) Need to do further research on tobacco plants with productivity measurement until harvest time. 2) It is necessary to conduct further research on various potential crops for the industry.

\section{REFERENCES}

[1] Alonso, M., and E. J. Finn. 1992. Basics of University Physics (vol. 2) Field and Wave. Translation by Lea Prasetyo and Kusnul Hadi. Jakarta: Erlangga.

[2] Belyvaskaya, N.A. 2004. Bological Effects Due To Magnetic Field on Plants. Adv Space res, 34 (7): 66-7.

[3] Bernhart, J.H., J. Brix, and E. Vogel. 2017. Esabilished Viological Effects of Extremely Low Frequency (ELF) Fields, Current Protection Concepts, and Research Needs.

[4] El-Ghizawi et al. 2016. Effect of Magnetic Field Treatments on Germination of True Potato Seeds, Seedlings Growth and Potato Tubers Characteristics. Middle East Journal of Agriculture Research. Vol 05 No. 01 Page74-81.

[5] European Health Risk Assesment Network on Electromagnetic Field Exposure (EFHRAN). 2010. Risk Analysis Of Human Exposure To Electromagnetic Fields. European Health Risk Assessment Network on Electromagnetic Fields Exposure.

[6] Fauziah, Annisa'ul. 2015. The Influence of Magnetic Field Exposure on Germination of Majol Seed Dates. Malang.

[7] Fernando R.M et al. 2014. Effects Of Magnetic Field Irradiation On Broccoli Seed With Accelerated Aging. Jurnal Acta Agrophysica. Vol 21 No. 1 Page. 63-67.

[8] Hozayn et al. 2015. Effect of Magnetic Field on Germination, Seedlings Growth and Cytogenetic of Onion. African Journal of Agriculure. Vol 10. Page 850-859.

[9] Jedlička, J., Paulen, O. and Ailer, Š. 2014. Influence Of Magnetic Field On Germination, Growth And Production Of Tomato. Scientific Journal for Food Industry Potravinarstvo, 8(1): 150-154.

[10] Khurram Zias et al. 2015. Magnetic Field Can Improve Germination Potential and Early Seedling Vigor of Cabbage Seeds. Annual Research \& Review in Biology. Vol 6 No. 6 Page 391-340.

[11] M. Ayyoub Tanvir et al. 2012. Exploring the Groeth Potential of Albizia Procera and Leucaena Leucocephala as Influenced by Magnetic Fields. Turk Journal Agric. Vol 36 Page 757-763.

[12] Mardhika, Wulansari et al. 2017. Effect of Magnetic Field Induction Extremely Low Frequency ELF Against Growth of Ear Mushroom Heat. Jurnal Pembelajaran Fisika. Vol 6 No. 2 page 181-188.

[13] Nimmi, V. and Madhu, G. 2009. Effect Of Pre-Sowing Treatment With Permanent Magnetic Field On Germination And Growth Of Chilli (Capsicum annum. L.). Internasional Agrophysics, 2009(23): 195-198.

[14] Rãcuciu, M., Creangã, D. dan Horga, I. 2006. Plant Growth Under Static Magnetic Field Influence. Rom.Journ.Phys, 53(1-2): 353-359.

[15] Reza Emilia et al. 2015. Application of Magnet Field Extremely Low Frequency (ELF) $100 \mu \mathrm{T}$ and $300 \mu \mathrm{T}$ On Ranti Tomato Plant Growth. Jurnal Pendidikan Fisika. Vol. 4 No. 2 page 164-170.

[16] Saragih, H., J., and Silaban, O. 2010. Increasing the Growth Rate of Soybean Growth With The Aided Magnetic Field Static. Proceedings of the National Seminar on Physics. UAI : Bandung.

[17] Shabrangi, A., Majd, A., Sheidai, M., Nabyouni, M., and Dorranian, D. 2010. Extremely Low Frequency Electromagnetic Fields on The Antioxidant Enzymes Activity of C3 and C4 Plants, Progress In Electromagnetics Research Symposium Proceding, Cambridge, USA.

[18] Sudarti dan Heliatin. 2005. The Effect Of Alteration 11-10 To The Immune Modulation Response On Bul/C Mice Exposed Extremely Low Frequency Magnetic Field 20 MT. jurnal saintifika, 6(1):46-44. Jember: Universitas Jember.

[19] Sudarti et al. 2017. Analysis of Extremely Low Frequency (ELF) Magnetic Field Effect to Oyster Mushroom Productivity. International Jurnal of Advanced Engineering Research and Science, Vol. 4(10). IJAERS.

[20] Tarigan, T. R. P. 2013. Study of Radiation Levels of Electromagnetic Fields Generated by Phones.

[21] Seluler. Electric Tehnic Journal Tanjungpura University. 1(1).

[22] Valberg PA, Kevet R, Rafferty CN, 1997, Can low-level 50/60 Hz electric and magnetic fields cause biological effects ?, Published erratum appears in radiat Res 1997 N0v;148(5):528. Radiat Res Jul:148(1):2-21

[23] Winandari,O.P, 2011. Germination and Growth of Tomato (Lycopersicum esculentum Mill.) Under the Old Influence of Different Magnetic Field Exposure. Thesis. Bandar Lampung: Universitas Lampung.

[24] World Health Organizaion (WHO). 2014. Enviromental Health Criteria Extremely Low Frequency Field. Geneva: WHO Press.

[25] Yalcin, S. dan Erdem, G. 2012. Biological Effect of Electromagnetic Fields (Review). African Journal of Biotechnology vol. 11(17) :3933-3941.

[26] Young, H.G. 2012. College Physics 9th Edition. San Fransisco: Person Education, Inc. 